\title{
Assessing Predictors of Academic Performance for NMEI Curriculum-Based Medical Students Found in the Southern Ethiopia
}

\author{
Tsegaye Mehare $\mathbb{D}^{D},{ }^{1}$ Reta Kassa, ${ }^{2}$ Birhanie Mekuriaw, ${ }^{3}$ and Tewodros Mengesha ${ }^{1}$ \\ ${ }^{1}$ Department of Biomedical Science, College of Medicine and Health Sciences, Dilla University, Dilla, Ethiopia \\ ${ }^{2}$ School of Public Health, College of Medicine and Health Sciences, Dilla University, Dilla, Ethiopia \\ ${ }^{3}$ Department of Psychiatry, College of Medicine and Health Science, Dilla University, Dilla, Ethiopia
}

Correspondence should be addressed to Tsegaye Mehare; tseyeshe96@gmail.com

Received 15 August 2020; Revised 15 September 2020; Accepted 24 September 2020; Published 6 October 2020

Academic Editor: Jieming Ma

Copyright (C) 2020 Tsegaye Mehare et al. This is an open access article distributed under the Creative Commons Attribution License, which permits unrestricted use, distribution, and reproduction in any medium, provided the original work is properly cited.

\begin{abstract}
Background. In Ethiopia since 2012, the Ethiopian Federal Ministry of Health and Education implemented a new medical education initiative in 13 institutions. Currently, as a nation, very little is known about the predictors of academic performance for new medical education curriculum-based students. Identifying different factors affecting students' academic performance in the local context so as to enrich the empirical evidence and provide new insights into the effect of variables in developing countries is very important. Thus, the main aim of this study was to assess predictors of academic performance for new medical education initiative curriculum-based medical students. Objective. This study designed to assess the predictors of academic performance for new medical education initiative curriculum-based medical students found in Southern Nations and Nationalities Peoples' Region, Ethiopia. Methods. Institutional-based cross-sectional study design was used on 472 new medical education system students. The study setting includes three medical institutions (Dilla University College of Medicine and Health Science, Wolaita Sodo University College of Medicine and Health Sciences, and Yirgalem Hospital Medical College) within southern region from February to July 2020. The study subjects were those medical students under the NMEI curriculum and had at least one-year cumulative grade point average in the abovementioned institutions. Results. A total of 167 (35.4\%) of the students' academic performance scores were poor. Being agriculture graduate with educational background, mothers with no formal education, being married, first-degree performance score of 2.7-3.2 CGPA, monthly allowance of 10-24.99 USD, nondormitory, student age of 31-35 years old, and being stressed have shown an association with poor academic performance score of the students. Conclusion. First-degree educational background, marital status, maternal educational status, first-degree academic performance, age of the student, monthly allowance, residency during medical school, and history of stress were significant predictors of academic performance for new medical education system students. Thus, it is recommended that special attention should be paid to the admission criteria and financial support of the students.
\end{abstract}

\section{Background}

Medical education has been discussed for its system, aim, and structure for many years. Recently, it is more reformed to produce more competent medical professionals [1-3]. Changes are primarily aimed at maximizing the competencies through providing contextual, problem-oriented, and self-directed learning. Education is meaningful when students integrate the knowledge of basic science facts into clinical problems so that the quality of health care is achieved, and of course, this would be real with good achievements of academic qualities [2, 4].

Ethiopia has been implementing traditional medical education and graduates were missing some competencies [5]. Studies elsewhere reported that students were passively engaged in the educational process and courses are discrete 
and discipline-based [6]. Since 2012, the Ethiopian Federal Ministry of Health and Education implemented a new medical education initiative (NMEI) in 13 institutions $[5,7]$. NMEI utilizes modern educational principles like self-directed learning, problem-based learning (PBL), and professional competency development (PCD) [8, 9]. The curriculum utilizes a modular system and provides horizontal and vertical integration of basic and clinical courses. During the first three years of study, PBL, PCD, and community attachment sessions are focused on; assisted by lectures, skills training, basic science laboratory, and clinical attachments. Social and population health courses are longitudinally given throughout the students' study [5]. Empirical evidence showed that PBL stimulates communication skills, deep learning, and a better understanding of medical competencies [8]. Research has shown that it helps integrating basic sciences to clinical courses at earlier years of medical education $[1,8,9]$.

The information on the predictors of academic performance among traditional medical education students was documented at different times and places in Ethiopia [10-12]. A study on predictors of self-reported academic performance among undergraduate medical students of Hawassa University showed that substance use at university, medicine as first choice by students, and university entrance examination results were identified as predictors of variation in self-reported academic performance [10]. A study done in Jimma University Medical School reported that stress was a significant problem among medical students and had a negative impact on their academic performance [11]. Another study done in Wolaita Sodo University showed that grade 12 average mark, university entrance exam score, and socioeconomic variables were identified as predictors of academic achievement for first-year students [12].

Besides, a study done at the University of Ghana School of Medicine and Dentistry, Ghana, on evaluation of sleep patterns and self-reported academic performance among medical students reported that sleep quality associated with academic performance [13] while the study done at the Saudi Medical College in 2019 is in contrary, which indicated that poor sleep or stress did not show any significant association with academic performance [14]. Currently as a nation (Ethiopia), very little is known about the predictors of academic performance for NMEI curriculum-based students. Pilot reports in Ethiopia showed that even though NMEI utilizes modern educational principles, students are poorly performing in the qualifying exams [15]. Pieces of evidence from SWOT analysis showed that there is a problem with the admission policy. Therefore, this study is very important to identify factors affecting students' academic performance in the local context and enrich the empirical evidence in the developing nations and help to provide new insights into the effect of variables in developing countries, where curricular experts and national policy makers use productively to design and implement policies that improve the students' performance and educational quality accordingly. In addition, this study result provides baseline resource in the catchment area for other researchers. The research question is: What are the predictors of academic performance for new medical education initiative curriculum-based medical students found in Southern Nation and Nationalities and Peoples' Region (SNNPR), Ethiopia?

\section{Materials and Methods}

2.1. Study Context. The study was conducted in three medical schools in SNNPR which teach medical students through new medical education innovative curriculum. The medical schools with new medical education curriculumbased initiatives were established in 2012. Applicants with a first degree in health science, computational science, and agriculture educational background were considered for admission to NMEI schools. The main feature of the NMEI program is integrating basic sciences to clinical skills complemented by early clinical and frequent community exposure, PBL, and PCD where all need the active engagement of the students $[5,7]$.

The study duration is five years. Students study the normal and abnormal function and structure of human body for the first two years, followed by two clinical years and the final one year is block internship time. The grading system of the school is based on the fixed-scale system of NMEI curriculum with $90 \%-100 \%(\mathrm{~A}+), 85 \%-89.9 \%(\mathrm{~A}), 80 \%-$ $84.9 \%(\mathrm{~B}+), 70 \%-79.9 \%(\mathrm{~B}), 65 \%-69.9 \%(\mathrm{C}+), 60 \%-64.9 \%$ (C), $55 \%-59.9 \%(\mathrm{D}+), 50 \%-54.9 \%$ (D), and less than $50 \%$ (F). According to the system, A+ and A have a score of 4.0 whereas $\mathrm{B}+, \mathrm{B}, \mathrm{C}+, \mathrm{C}, \mathrm{D}$, and $\mathrm{F}$ have scores of 3.5, 3.0, 2.5, $2.0,1.0$, and 0 , respectively $[5,16]$. Accordingly, the maximum and the minimum cumulative grade point average (CGPA) a medical student can achieve will be 4.0 and 0 , respectively.

2.2. Study Design and Setting. Institution-based cross-sectional study design was conducted. The study was conducted in medical schools with the NMEI curriculum found in the SNNP region from February to July 2020. All the three medical schools (Dilla University College of Medicine and Health Science; Wolaita Sodo University, College of Medicine and Health Sciences and Yirgalem Hospital Medical College) found in Southern Nation Nationalities and People's Region with NMEI curriculum were included.

2.3. Sample Size. The number of students in all three medical schools who had computed 1st-year CGPA was less than 500. Since the number of students in all the three medical schools was small to carry out random sampling, we were using the entire available plus eligible 476 students.

2.4. Source Population. All medical students admitted to the NMEI curriculum at Dilla University, Wolaita Sodo University, and Yirgalem Hospital Medical College were the source population.

2.5. Study Population. All NMEI students from three medical schools whose 1st-year CGPA at least calculated were included in the study. 
2.5.1. Inclusion Criteria. Students whose 1st-year CGPA was computed at least.

2.5.2. Exclusion Criteria. Students who had not at least one complete year CGPA. Besides, students who were seriously sick at the time of data collection.

2.6. Data Collection Tool and Procedure. Data were collected using structured self-administered questionnaires. If students fail to remember their CGPA, it was collected from the registrar and alumni office because the formal institutional letter of cooperation was already submitted to the registrar and alumni office of the corresponding institution. The questionnaire was prepared in English and then translated into Amharic, a federal institution language. The questionnaire consisted of items assessing sociodemographic characteristics of students and education-related factors. Three experienced higher diploma program graduate teachers for data collection and two experienced Master of Science (MSc) graduate health professionals for supervision were recruited. One-day training was given for data collectors and a pretest was done on 47 samples out of the main study area. During the pretest, the questionnaire was assessed for its clarity, understandability, completeness, and time consumption. The principal investigator and supervisors supervise the data collectors' data collection process as if it was per the standard. The investigators reviewed and checked the data each day after data collection for its completeness and accuracy.

\subsection{Operational Definition}

Poor academic performance score: students who scored $<3.2$ cumulative grade point average

Good academic performance score: students who scored $\geq 3.2$ cumulative grade point average

2.8. Ethical Approval and Consent to Participate. Ethical clearance was obtained from Dilla University, Centre for Educational Studies and Research. An official letter of cooperation was distributed to each of the data collection sites. Before the questionnaire, the aims and objectives of the study were clearly explained to the participants. Verbal informed consent was obtained from each study participant before data collection. Confidentiality of the data was maintained by excluding their identifiers. All participants were involved in this study only with their willingness.

2.9. Statistical Analysis. The entire data collected using a structured questionnaire were validated, edited, coded, and entered into SPSS version 23. Followed by checking for any inconsistencies, descriptive analysis was performed. Descriptive statistics, such as frequencies, and percentages were used to describe the sociodemographic and educational background, substance use history in the campus, and CGPA of the students. A chi-square test was used to find the potential association of dependent and independent variables. Bivariate logistic regression analysis was done to decide whether there is an association between academic performance and different factors to select nominee variables for multivariate logistic regression. Variables with $p$ values of up to 0.20 in the bivariate logistic regression analysis were identified and fitted to the multiple logistic regression analysis to identify the independent effects of each variable to the outcome variable. The odds ratio with 95\% confidence intervals (CI) was calculated to distinguish the occurrence and strength of associations, and statistical significance was affirmed if $p<0.05$.

\section{Results}

3.1. Sociodemographic Characteristics. In this study, a total of 472 students from the three medical schools were included giving a response rate of $99.2 \%$. Of the total number of respondents, $35.3 \%$ were in the preclinical year two, and the remaining $64.7 \%$ were in the clinical years. Nearly threequarters (73.5\%) of the participants were male, and the mean age of the participants was $33.08 \pm 4.13$ years. Participants reported an average monthly allowance of $32.49 \pm 21.98$ USD. The predominant religion of the study population was found to be Protestant, 244 (51.7), followed by Orthodox, 98 (20.8\%), and Muslim, 75 (15.9\%), while the rest were neither Christians nor Muslims. The predominant ethnic group was 141 (29.9\%) Amhara followed by Oromo 128 (27.1\%). Analysis of educational levels of mothers showed that the majority 147 (31.2\%) had primary education, $111(23.5 \%)$ had no formal education, and 110 (23.3\%) grade 7-8 education while the rest $104(22.0 \%)$ had secondary school and above levels of educational (Table 1).

3.2. Education-Related Factors. With regard to first-degree educational background, nearly half (49.8\%) of participants graduated with their first degree in agriculture and the average CGPA performance score was $3.35 \pm 0.38$. The average self-reported medical school entrance examination result was $82.24 \% \pm 8.19 \%$. There was not a statistically significant difference between the mean entrance examination results of male and female students $(82.66 \%$ versus $81.06 \%$, resp., $p=0.061$ ). The average self-reported work experience before joining medical school was $3.22 \% \pm 1.39$ years. Of the total number of participants, more than a quarter $(28.6 \%)$ used any substances during the data collection period. Cigarettes, alcohol, and Khat together were the most commonly used substance, followed by alcohol and Khat chewing. When substance use was disaggregated by academic year, the proportion of substance users increased with increment in the academic year. The students' mean lengths of time usually spent studying in 24 hours were $6.22 \pm 3.46$ hours (Table 2).

The self-reported academic performance had been decreasing as the academic years progressed, with the highest and lowest performance being in preclinical I (mean GPA 3.14) and clinical I medicine (mean GPA $2.81)$, respectively. The mean current cumulative GPA of the participants was $3.1 \pm 0.33$; more than half $(64.6 \%)$ of 
TABLE 1: Sociodemographic characteristics of new medical education system students in SNNPR.

\begin{tabular}{|c|c|c|}
\hline Characteristics & Frequency & Percent \\
\hline \multicolumn{3}{|l|}{ Sex } \\
\hline Male & 347 & 73.5 \\
\hline Female & 125 & 26.5 \\
\hline \multicolumn{3}{|l|}{ Age category in years } \\
\hline $25-30$ yrs & 116 & 24.6 \\
\hline $31-35$ yrs & 197 & 41.7 \\
\hline$>35$ yrs & 159 & 33.7 \\
\hline \multicolumn{3}{|l|}{ Residency during medical school } \\
\hline Dormitory & 369 & 78.2 \\
\hline Nondormitory & 103 & 21.8 \\
\hline \multicolumn{3}{|l|}{ Marital status } \\
\hline Unmarried & 223 & 47.2 \\
\hline Divorced & 115 & 24.4 \\
\hline Married & 134 & 28.4 \\
\hline \multicolumn{3}{|l|}{ Medical education status } \\
\hline Preclinical II & 167 & 35.3 \\
\hline Clinical I & 150 & 31.8 \\
\hline Clinical II & 97 & 20.6 \\
\hline Internship & 58 & 12.3 \\
\hline \multicolumn{3}{|l|}{ Monthly allowance, USD } \\
\hline$<10$ & 121 & 25.6 \\
\hline $10-24.99$ & 105 & 22.3 \\
\hline $25-50$ & 118 & 25.0 \\
\hline$>50$ & 128 & 27.1 \\
\hline \multicolumn{3}{|l|}{ Ethnicity } \\
\hline Amhara & 141 & 29.9 \\
\hline Oromo & 128 & 27.1 \\
\hline Wolaita & 80 & 17.0 \\
\hline Gurage & 63 & 13.3 \\
\hline Others & 60 & 12.7 \\
\hline \multicolumn{3}{|l|}{ Religion } \\
\hline Protestant & 244 & 51.7 \\
\hline Orthodox & 98 & 20.8 \\
\hline Muslim & 75 & 15.9 \\
\hline Others & 55 & 11.7 \\
\hline \multicolumn{3}{|l|}{ Maternal education level } \\
\hline No formal education & 111 & 23.5 \\
\hline Primary education & 147 & 31.2 \\
\hline Grade $7-8$ education & 110 & 23.3 \\
\hline Secondary and above education & 104 & 22.0 \\
\hline \multicolumn{3}{|l|}{ Paternal education level } \\
\hline No formal education & 68 & 14.4 \\
\hline Primary education & 34 & 7.2 \\
\hline Grade 7-8 education & 33 & 7.0 \\
\hline Secondary and above education & 337 & 71.4 \\
\hline
\end{tabular}

the students had a cumulative GPA $\geq 3.2$, and there was no difference in cumulative GPA between female and male students (3.14 and 3.11, $p=0.4$ ). In addition, there was no difference in cumulative GPA between preclinical and clinical students (3.15 and 3.10, $p=0.14$, Table 3). More than one-third of the participants (34.1\%) had ever been delayed (needed to repeat a course) in their time as medical students; nonetheless, $11.6 \%$ had needed to resit an examination. The academic performance was good for $64.6 \%$ of the students (cumulative GPA of $\geq 3.2$ ). Poor
TABLE 2: Former first-degree educational background and behavioral characteristics of new medical education system students in SNNPR.

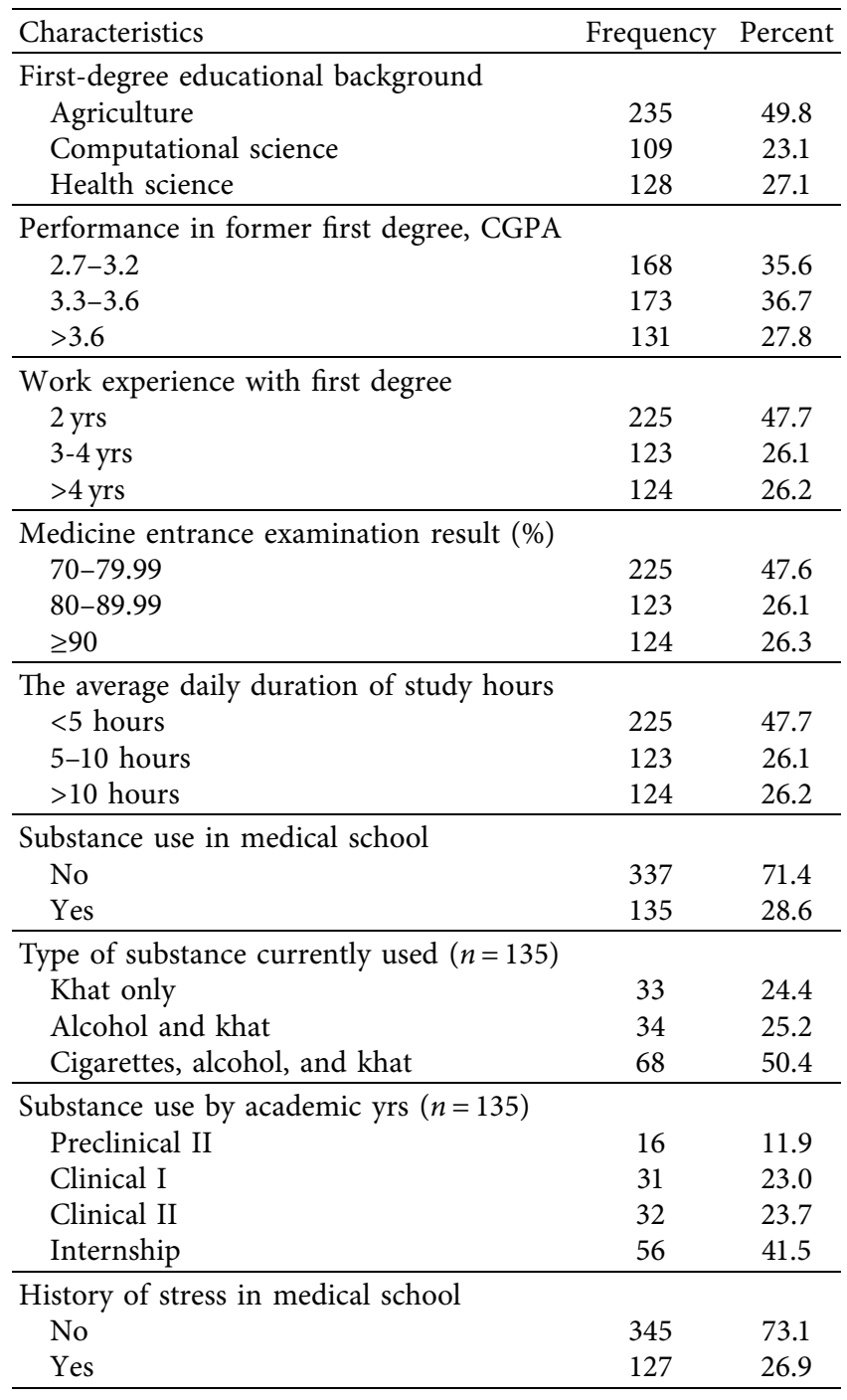

academic performance (cumulative GPA <3.2) was reported by $35.4 \%$ of the students (Table 3 ).

3.3. Predictors of Academic Performance. The bivariate logistic regression analysis showed that maternal educational status, paternal educational status, marital status, age of the student, monthly allowance, average study hour per day, residency during medical school, medicine entrance exam result, first-degree educational background, substance use in campus, first-degree performance score, and history of stress were associated with academic performance. After adjustments for possible effects of confounding variables, maternal educational status, marital status, age of the student, monthly allowance, residency during medical school, firstdegree educational background, first-degree performance score, and history of stress were significantly and strongly associated with academic performance of the students.

Students who were graduated with their first degree in agriculture showed a significant association with poor 
TABle 3: Patterns of academic performance among new medical education system students in SNNPR.

\begin{tabular}{lcc}
\hline Have you ever been delayed (repeated) course? & & \\
No & 311 & 65.9 \\
Yes & 161 & 34.1 \\
\hline Academic year of delay $(n=161)$ & & \\
Preclinical II & 39 & 24.2 \\
Clinical I & 37 & 23.0 \\
Clinical II & 26 & 16.1 \\
Internship & 59 & 36.7 \\
\hline Have you ever had a resit exam? & \\
No & 417 & 88.4 \\
Yes & 55 & 11.6 \\
\hline The academic year of the resit exam $(n=55)$ & & \\
Preclinical II & 14 & 25.5 \\
Clinical I & 11 & 20.0 \\
Clinical II & 9 & 16.4 \\
Internship & 21 & 38.1 \\
\hline Withdrawal history in any case & & \\
No & 405 & 85.8 \\
Yes & 67 & 14.2 \\
\hline GPA & Mean & SD \\
Preclinical I & 3.14 & 0.34 \\
Preclinical II & 2.90 & 0.26 \\
Clinical I & 2.81 & 0.28 \\
Clinical II & 2.74 & 0.28 \\
Current cumulative & 3.1 & 0.33 \\
\hline Academic performance, cumulative GPA & \\
Good ( $\geq 3.2)$ & 305 & 64.6 \\
Poor (<3.2) & 167 & 35.4 \\
\hline
\end{tabular}

academic performance. In epidemiological explanation, this showed us that students who graduated with their first degree in agriculture were 9.58 times more likely to score poor academic performance as compared to those students who graduated with their first degree in health science (AOR: 9.58, 95\% CI 4.51, 20.36). The likelihood of scoring poor academic performance among students who had mothers with no formal education were 4.58 times more compared to students who had mothers with a secondary and above level of education (AOR: 4.58, 95\% CI 1.99, 10.54). Being married was strongly associated with poor academic performance. Those students who were married were 4.32 times more likely to score poor academic performance as compared to unmarried (AOR: $4.32,95 \%$ CI $2.43,7.68)$. Student first-degree performance score was another variable associated with academic performance in medical school. Those students who scored 2.7-3.2 CGPA during their first-degree education were 3.07 times (AOR: $3.07,95 \%$ CI $1.62,5.81$ ) more likely to perform poor CGPA in medical school as compared with those students who scored >3.6 CGPA in their first-degree education.

Students who earned a monthly allowance of 10-24.99 USD were 3.58 times as likely to score poor academic performance (AOR: 3.58, 95\% CI 1.70, 7.56) than students who earned $>50$ USD. Being a nondormitory was also associated with poor academic performance. Those students who were nondormitory were 2.49 times more likely to score poor academic performance compared with their counterparts (AOR: $2.49,95 \%$ CI 1.39, 4.46). On the other hand, we noted an association between students' age and academic performance. Students who had age between 31 and 35 years old had a lower risk of scoring poor academic performance as compared to those students who had age between 25 and 30 years old (AOR $0.30,95 \%$ CI $0.20-0.44$ ) (Table 4).

\section{Discussion}

According to this study result, both educational and sociodemographic factors were a substantial predictor for academic performance of medical students. Poor academic performance was found to be significantly higher in those students who were graduated with their first degree in agriculture than those who graduated in health science. This may be related to the exposure deficit in medical knowledge for those students whose first-degree educational background was agriculture. Maternal educational status was another important variable associated with student's poor academic performance. Poor academic performance was higher for those students whose mothers had no formal education as compared to those students whose mothers had high school and above level of education. This might be explained by the fact that mothers might support morally, psychologically, and economically, thus providing a positive triggering factor for their children to be successful [17]. Similarly, marital status enlightened a significant association with poor academic performance scores. Married students had higher odds to scored poor academic performance than unmarried students. The possible rationalization for this difference is that marrieds are in stress to fulfill social and financial economies for their family in addition to academic stress. Monthly allowance was also another associated factor for poor academic performance scores. Those students whose monthly allowance was 10-24.99 USD scored poor academic performance as compared to those students whose monthly allowance was $>50$ USD. This finding is in line with studies done in Jimma University [11] and Canada memorial's medical students [18]. This might be explained by the fact that students' financial constraints could be an additional source of stress besides academic stressors which might result in poor academic performance. Even though food and dormitory services are provided to the students by the university, students need money for jaunts, stationaries, to buy dressings, and other necessities. However, the current result is contrary to the study done in Southeast Nigeria [19]. The possible rationalization we speculate that the less financial capability for a medical student has, the less probable $s /$ he would be engaged in extracurricular activities, hence the more likely s/he would focus on academic-related activities.

Poor academic performance was found to be significantly higher in those students who scored 2.7-3.2 CGPA on their first degree than those scored >3.6 CGPA on their first degree. This finding is in agreement with studies done at Arabian Gulf University (Bahrain) [20], Scotland medical school applicants [21], and United Kingdom school leaver entrants for medical school [22]. The possible rationalization could be that a previous academic achievement is a stronger 
TABLE 4: Binary and multiple logistic regression analysis of academic performance based on CGPA as a dichotomous variable, for new medical education system students in SNNPR.

\begin{tabular}{|c|c|c|c|c|}
\hline \multirow{2}{*}{ Variables } & \multicolumn{2}{|c|}{ Academic performance, CGPA } & \multirow{2}{*}{ COR $(95 \% \mathrm{CI})$} & \multirow{2}{*}{ AOR (95\% CI) } \\
\hline & Good $(\geq 3.2)$ & Low $(<3.2)$ & & \\
\hline \multicolumn{5}{|l|}{ Paternal educational status } \\
\hline No formal education & 12 & 56 & $8.02(4.14,15.54)$ & $4.58(1.99,10.54)^{* * *}$ \\
\hline Primary education & 27 & 7 & $0.45(0.19,1.05)$ & $0.44(0.14,1.35)$ \\
\hline Grade $7-8$ education & 25 & 8 & $0.55(0.24,1.26)$ & $2.83(0.93,8.58)$ \\
\hline Secondary and above education & 213 & 124 & Ref & Ref \\
\hline \multicolumn{5}{|l|}{ Age } \\
\hline $25-30$ yrs & 54 & 62 & Ref & Ref \\
\hline $31-35$ yrs & 129 & 68 & $1.66(1.03,2.69)$ & $0.34(0.16,0.71)^{* *}$ \\
\hline$>35$ yrs & 94 & 65 & $0.76(0.50,1.17)$ & $1.46(0.63,3.37)$ \\
\hline \multicolumn{5}{|l|}{ Residency during medical school } \\
\hline Dormitory & 223 & 146 & Ref & Ref \\
\hline Nondormitory & 54 & 49 & $1.39(0.89,2.15)$ & $2.49(1.39,4.46)^{* *}$ \\
\hline \multicolumn{5}{|l|}{ Marital status } \\
\hline Unmarried & 152 & 71 & Ref & Ref \\
\hline Divorced & 84 & 31 & $0.79(0.48,1.30)$ & $0.85(0.47,1.53)$ \\
\hline Married & 41 & 93 & $4.86(3.06,7.72)$ & $4.32(2.43,7.68)^{* * * *}$ \\
\hline \multicolumn{5}{|l|}{ Monthly allowance } \\
\hline$<10$ & 47 & 74 & $3.73(2.20,6.31)$ & $2.64(1.31,5.34)^{* *}$ \\
\hline $10-24.99$ & 61 & 44 & $1.71(0.99,2.94)$ & $3.58(1.70,7.56)^{* *}$ \\
\hline $25-50$ & 79 & 39 & $1.17(0.68,2.01)$ & $0.54(0.24,1.21)$ \\
\hline$>50$ & 90 & 38 & Ref & Ref \\
\hline \multicolumn{5}{|l|}{ Frist degree educational background } \\
\hline Agriculture & 88 & 147 & $8.05(4.74,13.67)$ & $9.58(4.51,20.36)^{* * *}$ \\
\hline Computational science & 83 & 26 & $1.51(0.80,2.85)$ & $3.06(1.29,7.27)^{*}$ \\
\hline Health science & 106 & 22 & Ref & Ref \\
\hline \multicolumn{5}{|c|}{ Performance in former first degree, CGPA } \\
\hline $2.7-3.2$ & 82 & 86 & $2.15(1.34,3.45)$ & $3.07(1.62,5.81)^{* *}$ \\
\hline $3.3-3.6$ & 107 & 66 & $1.26(0.78,2.03)$ & $2.08(1.11,3.89)^{*}$ \\
\hline$>3.6$ & 88 & 43 & Ref & Ref \\
\hline \multicolumn{5}{|l|}{ History of stress } \\
\hline No & 213 & 124 & Ref & Ref \\
\hline Yes & 64 & 71 & $1.98(1.31,2.99)$ & $1.78(1.04,3.05)^{*}$ \\
\hline
\end{tabular}

predictor of medical school academic performance, but that predictive value decreased as students progressed through the academic years. This is because prior academic achievement demonstrates that the student has a minimum level of competence and the basic knowledge on which to build and integrate new knowledge [23]. Moreover, students age $>35$ years old were another variable associated with poor academic performance in this study. This study is in line with a study done in Hawassa University [10], even if the effect of student's age on academic performance at medical school is a controversial issue. According to several studies, as the students get older, scientific reasoning became less well and graded with lower scores in their medical studies [24, 25]. On the other hand, recent studies show that older and more mature medical students performed better than their younger counterparts [26].

The risk of poor academic performance was found to be significantly higher in those students who were nondormitory than those students who were dormitories. This may be related to the poor time management of nondormitory students such as spend more time in extracurricular activities, engage in social and familial duties. Lastly, a history of stress was another personal factor significantly associated with poor academic performance. Students who had stress during medical school were more likely to score poor academic performance as compared with nonstressed students. The current finding is supported by findings from Hawassa University [10] and Jimma University [11]. The possible rationalization could be that medical students are overloaded with a tremendous amount of reading materials, especially during preclinical encounters. They have limited time to internalize all the information studied. The overload information creates a feeling of distress and disappointments because they do not handle all topics covered and, therefore, are not successful during the examination period [27]. The other justification could be that an excessive amount of stress in medical training predisposes students to have difficulties in solving problems, reduced concentration, and that results in excessive secretion of a stress hormone cortisol that causes a decrement in memory retrieval functions of hippocampus and amygdala due to complete blockage of glucocorticoid receptors $[28,29]$. 


\section{Conclusion and Recommendation}

First-degree educational background, marital status, maternal educational status, first-degree academic performance, age of the student, monthly allowance, residency during medical school, and history of stress were significant predictors of NMEI students' academic performance. Thus, it is recommended that special attention should be given to the admission criteria and financial support of the students.

\section{Limitation of the Study}

Since the study was done on all the available and eligible students without sampling, the result might lack generalizability to the entire population in the catchment area.

\section{Abbreviations}

NMEI: New medical education initiative

CGPA: Cumulative grade point average

GPA: Grade point average

PBL: Problem-based learning

PCD: Professional competency development

OR: $\quad$ Adjusted odds ratio

CI: Confidence interval

SPSS: Statistical Package for Social Science

SNNPR: Southern Nation and Nationalities People's Region.

\section{Data Availability}

The data upon which the result is based could be accessed from the corresponding author upon request.

\section{Conflicts of Interest}

The authors report no conflicts of interest work.

\section{Acknowledgments}

The authors' deep appreciation goes to Dilla University, Centre for Educational Studies and Research, for appropriate review and authorization of this paper. The authors would also like to extend their gratitude to teachers in the data collection sites, data collectors, and supervisors for precious contributions to the success of this study.

\section{References}

[1] M. C. E. Gwee, "Globalization of problem-based learning (PBL): cross-cultural implications," The Kaohsiung Journal of Medical Sciences, vol. 24, pp. S14-S22, 2008.

[2] I. Polyzois, N. Claffey, and N. Mattheos, "Problem-based learning in academic health education. A systematic literature review," European Journal of Dental Education, vol. 14, no. 1, pp. 55-64, 2010.

[3] K. J. A. H. Prince, P. W. L. J. Van Eijs, H. P. A. Boshuizen, C. P. M. Van Der Vleuten, and A. J. J. A. Scherpbier, "General competencies of problem-based learning (PBL) and non-PBL graduates," Medical Education, vol. 39, no. 4, pp. 394-401, 2005.
[4] C. Onyon, "Problem-based learning: a review of the educational and psychological theory," The Clinical Teacher, vol. 9, no. 1, pp. 22-26, 2012.

[5] Y. Abraham and A. Azaje, "The new innovative medical education system in Ethiopia: background and development," Ethiopian Journal of Health Development, vol. 27, no. 1, pp. 36-40, 2013.

[6] D. F. Wood, "ABC of learning and teaching in medicine: problem based learning," BMJ, vol. 326, no. 7384, pp. 328-330, 2003.

[7] C. M. Kelly, H. Vins, J. O. Spicer et al., "The rapid scale up of medical education in Ethiopia: medical student experiences and the role of e-learning at Addis Ababa University," PLoS One, vol. 14, no. 9, 2019.

[8] D. Dolmans and H. Schmidt, "The advantages of problembased curricula," Postgraduate Medical Journal, vol. 72, no. 851, pp. 535-538, 1996.

[9] H.-J. So and B. Kim, "Learning about problem based learning: student teachers integrating technology, pedagogy and content knowledge," Australasian Journal of Educational Technology, vol. 25, no. 1, 2009.

[10] A. Gedefaw, B. Tilahun, and A. Asefa, "Predictors of selfreported academic performance among undergraduate medical students of Hawassa University, Ethiopia," Advances in Medical Education and Practice, vol. 6, pp. 305-315, 2015.

[11] L. Melaku, A. Mossie, and A. Negash, "Stress among medical students and its association with substance use and academic performance," Journal of Biomedical Education, vol. 2015, Article ID 149509, 9 pages, 2015.

[12] Z. Zekarias, N. Aba-Milki, and F. Mikre, "Predictors of academic achievement for first year students. The case of Wolaita-Soddo university, Ethiopia," European Scientific Journal, vol. 11, no. 28, 2015.

[13] H. J. Lawson, J. T. Wellens-Mensah, and S. Attah Nantogma, "Evaluation of sleep patterns and self-reported academic performance among medical students at the University of Ghana school of medicine and dentistry," Sleep Disorders, vol. 2019, Article ID 1278579, 8 pages, 2019.

[14] A. D. Alotaibi, F. M. Alosaimi, A. A. Alajlan, and K. A. B. Abdulrahman, "The relationship between sleep quality, stress, and academic performance among medical students," Journal of Family \& Community Medicine, vol. 27, no. 1, p. 23, 2020.

[15] FMOH, Competency Assessment Study of GPs in Ethiopia: A Preliminary Report, FMOH, Addis Ababa, Ethiopia, 2009.

[16] A. Semu, Challanges in Problem Based Learning Implimentation in Debreberhan University, College of Medicine, Addis Ababa University, Debrebirhan, Ethiopia, 2016.

[17] G. Attili, P. Vermigli, and A. Roazzi, "Children's social competence, peer status, and the quality of mother-child and father-child relationships," European Psychologist, vol. 15, no. 1, pp. 23-33, 2010.

[18] J. Gushue, "Financial worries part of education for memorial's medical students," CMAJ, vol. 157, no. 5, pp. 559-562, 1997.

[19] U. Ekwochi, C. D. Osuorah, S. A. Ohayi, A. C. Nevo, I. K. Ndu, and S. Onah, "Determinants of academic performance in medical students: evidence from a medical school in southeast Nigeria," Advances in Medical Education and Practice, vol. 10, pp. 737-747, 2019.

[20] F. Alnasir and J. Abdel-Karim, "Prediction of medical students' performance in the medical school," Family Medicine \& Medical Science Research, vol. 2, no. 113, 2013.

[21] D. Powis, M. Bore, D. Munro, and M. A. Lumsden, "Development of the personal qualities assessment as a tool for 
selecting medical students," Journal of Adult and Continuing Education, vol. 11, no. 1, pp. 3-14, 2005.

[22] I. C. McManus, D. A. Powis, R. Wakeford, E. Ferguson, D. James, and P. Richards, "Intellectual aptitude tests and A levels for selecting UK school leaver entrants for medical school," BMJ, vol. 331, no. 7516, pp. 555-559, 2005.

[23] M. Weiss, I. Lotan, H. Kedar, and G. Ben-shakhar, "Selecting candidates for a medical school: an evaluation of a selection model based on cognitive and personality predictors," Medical Education, vol. 22, no. 6, pp. 492-497, 1988.

[24] K. L. Huff and D. Fang, "When are students most at risk of encountering academic difficulty? A study of the 1992 matriculants to U.S. medical schools," Academic Medicine, vol. 74, no. 4, pp. 454-460, 1999.

[25] F. Kay-Lambkin, S. A. Pearson, and I. Rolfe, "The influence of admissions variables on first year medical school performance: a study from Newcastle University, Australia," Medical Education, vol. 36, no. 2, pp. 154-159, 2002.

[26] D. James and C. Chilvers, "Academic and non-academic predictors of success on the Nottingham undergraduate medical course 1970-1995," Medical Education, vol. 35, no. 11 , pp. 1056-1064, 2001.

[27] M. S. B. Yusoff, A. F. Abdul Rahim, A. A. Baba, S. B. Ismail, M. N. Mat Pa, and A. R. Esa, "Prevalence and associated factors of stress, anxiety and depression among prospective medical students," Asian Journal of Psychiatry, vol. 6, no. 2, pp. 128-133, 2013.

[28] S. Kuhlmann, M. Piel, and O. T. Wolf, "Impaired memory retrieval after psychosocial stress in healthy young men," Journal of Neuroscience, vol. 25, no. 11, pp. 2977-2982, 2005.

[29] N. Y. Oei, B. M. Elzinga, O. T. Wolf et al., "Glucocorticoids decrease hippocampal and prefrontal activation during declarative memory retrieval in young men," Brain Imaging and Behavior, vol. 1, no. 1-2, pp. 31-41, 2007. 